INTERNATIONAL RESEARCH JOURNAL OF PHARMACY

www.irjponline.com

ISSN $2230-8407$

Research Article

\title{
SYNTHESIS AND GREEN BROMINATION OF SOME CHALCONES AND THEIR ANTIMICROBIAL SCREENING
}

Mayur R. Adokar*

Department of Chemistry, Sant Gadge Baba Amravati University, Amravati, India

Email: mayuradokar@rediffmail.com

Article Received on: 13/02/13 Revised on: 07/03/13 Approved for publication: 11/04/13

DOI: 10.7897/2230-8407.04438

IRJP is an official publication of Moksha Publishing House. Website: www.mokshaph.com

(C) All rights reserved.

\section{ABSTRACT}

Chalcones are the versatile molecules having the structural flexibility which permits structural transformations into flavonoids, flavanones, pyrazoles, oxazoles, pyrimidines etc. Changes in their structure have offered the development of new medicinal agents having improved pharmacological potency. Their derivatives have attracts increasing attention due to numerous pharmacological potential. In the present communication we report the synthesis of chalcones from various acetophenone derivatives with different aromatic aldehydes and green chemistry approach to their bromination with the help of Tetrabutylammonium Tribromide (TBATB). All the synthesized chalcone dibromides were screened for their antimicrobial activity against Aspergillus flavus, Rhizopus sp., Fusarium solani and Aspergillus niger.

KEYWORDS: Chalcone, brominated chalcones, Tetrabutylammonium Tribromide, antimicrobial activity.

\section{INTRODUCTION}

Chalcones are well known intermediate for synthesizing various heterocyclic compounds ${ }^{1}$. Chalcones are characterized by their possession of a $\mathrm{C}_{6}(\mathrm{~A})-\mathrm{CO}-\mathrm{CH}=\mathrm{CH}-\mathrm{C}_{6}$ (B) structure, two aromatic ring (A \& B) are linked by an aliphatic three-carbon chain which does not participate in forming a hetero ring as is usually found in other types of flavonoids compounds. A few dihydrochalcones $\mathrm{C}_{6}$ (A)-Co$\mathrm{CH}_{2}-\mathrm{CH}_{2}-\mathrm{C}_{6}$ (B) have been found though no evidence concerning the relationship between chalcones and dihydrochalcones or the co-existence of these two compounds is yet known.

Synthetic methods involve the condensation of ohydroxyacetophenone with substituted benzaldehyde in the presence of acidic or basic condensing agent $t^{2,3}$ to give a chalcone, flavanone or a mixture of these. However the suitable methods involve the condensation by means of alkali. Polymethoxy derivative condenses with 50 percent, 60 percent and 70 percent $^{4,5}$ potassium hydroxide in aqueous alcohol to give the chalcones.

Chalcones and flavanones are isomeric and undergo interconversion readily where acids or alkali acts as a catalyst and the change can take place in either direction, usually in acid medium the formation of the flavanone is more favoured in alkaline medium ${ }^{6}$. A considerable variety of methods are available for the preparation of polyhydroxy chalcones. However the methods for the preparation of chalcones show large number of variations. Higher concentration of alkali results self condensation of acetophenone. Whereas the lower concentration of alkali requires longer time for condensation.

Geiger and Conn during their chemical studies on the structure of clavioin found that a structural feature which was responsible for antibacterial activity was $\alpha, \beta$-unsaturated keto functional group ${ }^{7}$.

Green Chemistry is defined as invention, design, development and application of chemical products and processes to reduce or to eliminate the use and generation of substances hazardous to human health and environment. Professional developments involved in reinventing the use of materials. Understanding the challenge and prospective impact of Green Chemistry depends on some familiarity with the context of its adoption and practice. Bromination, especially of aromatic substrates, is usually carried out by elemental bromine ${ }^{8}$, but owing to hazards associated with bromine preferably organic ammonium tribromides (OATB), and pyridine hydrobromide perbromide are used. Because of smoothly with selective bromination of an activated aromatic ring in the presence of an olefinic double bond is possible with such a reagent. Several tribromides have been reported i.e, tetramethylammonium tribromide (TMATB) ${ }^{9}$ phenyltrimethylammonium tribromide $(\text { PTATB })^{10}$, tetrabutylammonium tribromide (TBATB) ${ }^{11}$.

The compounds with the backbone of chalcones have been reported to possess various biological activities such as antimicrobial, antioxidant ${ }^{12}$, anti-inflammatory, Analgesic, antiulcerative $^{13}$, antimalarial, anticancer ${ }^{14}$, antitubercular, antihyperglycemic ${ }^{15}$.

\section{MATERIALS AND METHODS}

Melting points reported were determined in a hot paraffin bath and are uncorrected. The IR spectra were recorded on SHIMADZU FTIR Presige-21 spectrophotometer mode 1310. H NMR spectra were recorded on Varian NMR Mercury-300 spectrometer in $\mathrm{CDCl} 3$ solvent with TMS as an internal standard.

General procedure for the preparation of chalcones (3a-e) To a cooled solution of $\mathrm{NaOH}$ and ethanol, acetophenone (0.043 mole) was added followed by the addition of substituted aromatic benzaldehyde $(0.043$ mole $)$, the reaction mixture was stirred for 2-3 hours till the mixture becomes viscous and then the mixture was kept overnight in a refrigerator. The separated product was filtered under suction and washed well with cold water. Then it was crystallized from rectified spirit.

\section{Synthesis of green reagent tetrabutylammonium tribromide (TBATB)}

A solution of $2.75 \mathrm{mmol}$ of $\mathrm{V}_{2} \mathrm{O}_{5}$ in $44.1 \mathrm{mmol}$ of $30 \% \mathrm{H}_{2} \mathrm{O}_{2}$ at $5{ }^{\circ} \mathrm{C}$ on reaction with $11 \mathrm{mmol}$ of TBAB in $7 \mathrm{ml}$ of water at ambient temperature produces yellow $\mathrm{Bu}_{4} \mathrm{NBr}_{3}$ (TBATB) 
with $70 \%$ yield. The yield can be raised to $97 \%$ by the use of a catalytic amount of $\mathrm{V}_{2} \mathrm{O}_{5}$ and dilute $\mathrm{H}_{2} \mathrm{SO}_{4}$ and two molar equivalent of $\mathrm{KBr}$. The product on crystallization from acetonitrile affords orange-yellow crystals with a sharp melting point of $75{ }^{0} \mathrm{C}$
General procedure for the bromination of chalcones (4ae)

To TBATB (1mmol) add Chalcone $(1 \mathrm{mmol})$ and water $0.5 \mathrm{ml}$, the whole mixture was mixed thoroughly and left at room temperature with occasional grinding for $15 \mathrm{~min}$. Upon completion of the reaction, $20 \mathrm{ml}$ of water was added to the reaction mixture and stirred for $10 \mathrm{~min}$. The reaction mixture was filtered, washed with water and air dried to afford the compounds.

\section{SCHEME}<smiles>[R]c1cc([R])c(C(C)=O)cc1[R]</smiles>

Where:

$$
\begin{array}{ll}
\text { a) } R^{\prime}=H, R^{\prime \prime}=H, R^{\prime \prime}=H ; & R^{1}=H, R^{3}=H, R^{2}=\mathrm{OCH}_{3} \\
\text { b) } R^{\prime}=H, R^{\prime \prime}=H, R^{\prime \prime}=H ; & R^{1}=\mathrm{NO}_{2}, R^{2}=H, R^{3}=H \\
\text { c) } R^{\prime}=\mathrm{NO}_{2}, \mathrm{R}^{\prime \prime}=\mathrm{H}, \mathrm{R}^{\prime \prime}=\mathrm{H} ; & \mathrm{R}^{1}=\mathrm{H}, \mathrm{R}^{2}=\mathrm{OCH}_{3}, \mathrm{R}^{3}=\mathrm{H} \\
\text { d) } \mathrm{R}^{\prime}=\mathrm{H}, \mathrm{R}^{\prime \prime}=\mathrm{Cl}, \mathrm{R}^{\prime \prime}=\mathrm{Cl} ; & \mathrm{R}^{1}=\mathrm{H}, \mathrm{R}^{2}=\mathrm{H}, \mathrm{R}^{3}=\mathrm{Cl} \\
\text { e) } \mathrm{R}^{\prime}=\mathrm{H}, \mathrm{R}^{\prime \prime}=\mathrm{H}, \mathrm{R}^{\prime \prime}=\mathrm{H} ; & \mathrm{R}^{1}=\mathrm{H}, \mathrm{R}^{2}=\mathrm{H}, \mathrm{R}^{3}=\mathrm{Cl}
\end{array}
$$<smiles>[R]c1cc([R7])c(C(=O)C(Br)C(Br)c2cc([R])c([R2])c([R])c2)cc1[R]</smiles>

$(4 a-e)$

4. 2,3-dibromo-3-(3-chlorophenyl)-1-(2,4dichlorophenyl)propan-1-one (4d):

White Solid, M.P. $=65^{\circ} \mathrm{c}$, Yield $=92 \%$, Elemental analysis for $\mathbf{C}_{15} \mathbf{H}_{\mathbf{9}} \mathbf{O C l}_{3} \mathbf{B r}_{2}$ : Found $\mathbf{C}=38.18, \mathbf{H}=1.87, \mathbf{B r}=33.86$, $\mathbf{C l}=22.53, \mathbf{O}=3.36$, Calculated $\mathbf{C}=38.22, \mathbf{H}=1.92, \mathbf{B r}=$ 33.90, $\mathbf{C l}=22.56, \mathbf{O}=3.39$., IR $\left(\mathbf{c m}^{-1}\right): 3067.40(\mathrm{Ar}-\mathrm{CH})$, $1694.14(\mathrm{C}=\mathrm{O}), 1592.07$ (C-C In ring), 782.16 (Ar-H), 577.22 (C-Br); ${ }^{1} \mathbf{H}$ NMR (סppm): 7.6 (d, 1H, Ar-H), 7.5 (s, 1H, Ar-H), 7.4(s, 1H, CH-C-Cl), 7.1(d, 1H, CH-C-Cl).

\section{2,3-dibromo-3-(3-chlorophenyl)-1-phenylpropan-1-one} (4e):

Pale Yellow Solid, M.P. $=58^{\circ} \mathrm{c}$ Yield $=94 \%$, Elemental analysis for $\mathbf{C}_{15} \mathbf{H}_{11} \mathbf{O C I B r}_{2}$ : Found $\mathbf{C}=44.72, \mathbf{H}=2.73, \mathbf{B r}=$ 39.67, $\mathbf{C l}=8.78, \mathbf{O}=3.74$, Calculated $\mathbf{C}=44.76, \mathbf{H}=2.75$, $\mathbf{B r}=39.70, \mathbf{C l}=8.81, \mathbf{O}=3.79 ., \mathbf{I R}\left(\mathbf{c m}^{-1}\right): 3065.47(\mathrm{Ar}-$ $\mathrm{CH}), 1690.87(\mathrm{C}=\mathrm{O}), 1590.12(\mathrm{C}-\mathrm{C}$ In ring), $675.59(\mathrm{Ar}-\mathrm{H})$, 580.59 (C-Br). ${ }^{1} \mathbf{H}$ NMR (סppm): 7.8 (d, 2H, Ar-H), 7.6 (dd, 1H, Ar-H), 7.5 (d,2H, Ar-H), 7.3 (d, 1H, CH-C-Cl). $\mathbf{B r}=38.66, \mathbf{N}=3.34, \mathbf{O}=11.58$, Calculated $\mathbf{C}=43.62, \mathbf{H}=$ 2.68, $\mathbf{B r}=38.69, \mathbf{N}=3.39, \mathbf{O}=11.62 . \mathbf{I R}(\mathbf{c m}-1): 3076.08$ (Ar-CH), 1690.17(C=O), 1595.25 (C-C In ring), 865.10 (Ar-H), 689.57 (C-Br); ${ }^{1} \mathbf{H}$ NMR (סppm): 8.10 (s, 1H, CH-C-NO $\left.{ }_{2}\right), 7.8$ (d, 2H, Ar-H), 7.5 (dd, 1H, Ar-H), 7.3 (d, 2H, Ar-H).

\section{2,3-dibromo-3-(4-methoxyphenyl)-1-(3-} nitrophenyl)propan-1-one (4c):

Brownish Yellow Solid, M.P. $=105^{\circ} \mathrm{c}$ Yield $=89 \%$, Elemental analysis for $\mathbf{C}_{\mathbf{1 6}} \mathbf{H}_{\mathbf{1 3}} \mathbf{N O}_{\mathbf{4}} \mathbf{B r}$ : Found $\mathbf{C}=43.32$, $\mathbf{H}=2.91, \mathbf{B r}=36.03, \mathbf{N}=3.09, \mathbf{O}=14.43$, Calculated $\mathbf{C}=$ 43.37, $\mathbf{H}=2.96, \mathbf{B r}=36.07, \mathbf{N}=3.16, \mathbf{O}=14.44 ., \mathbf{I R}\left(\mathrm{cm}^{-1}\right)$ : 3150 (Ar-CH), $1689.39(\mathrm{C}=\mathrm{O}), 1570.59$ (C-C In ring), $1532.0(\mathrm{~N}-\mathrm{O}), 823.15(\mathrm{Ar}-\mathrm{H}), 563.23$ (C-Br); ${ }^{1} \mathbf{H}$ NMR (סppm): $8.9\left(\mathrm{~s}, 1 \mathrm{H}, \mathrm{CH}-\mathrm{C}-\mathrm{NO}_{2}\right), 8.4(\mathrm{~d}, 1 \mathrm{H}, \mathrm{Ar}-\mathrm{H}), 8.2(\mathrm{~d}$, $1 \mathrm{H}, \mathrm{Ar}-\mathrm{H}), 7.9(\mathrm{~d}, 2 \mathrm{H}, \mathrm{Ar}-\mathrm{H}), 3.9\left(\mathrm{~s}, 3 \mathrm{H}, \mathrm{O}-\mathrm{CH}_{3}\right)$.

\section{Antimicrobial Screening}

Antimicrobial screening was done by using cup plate method at a concentration of $100 \mu \mathrm{g} / \mathrm{ml}$. The compounds were evaluated for antimicrobial activity against Rhizopus sp. Aspergillus flavus, Fusarium solani and Aspergillus niger. The results of antimicrobial data are summarized in table 1. All compounds show the moderate to good activity.

Table 1: Antimicrobial activity of test compounds

\begin{tabular}{|c|c|c|c|c|}
\hline Compounds & \multicolumn{4}{|c|}{ Zone of inhibition in mm. } \\
\cline { 2 - 5 } & $\begin{array}{c}\text { Rhizopus } \\
\text { sp. }\end{array}$ & $\begin{array}{c}\text { Aspergillus } \\
\text { flavus }\end{array}$ & $\begin{array}{c}\text { Fusarium } \\
\text { solani }\end{array}$ & $\begin{array}{c}\text { Aspergillus } \\
\text { niger }\end{array}$ \\
\hline 4a & 14 & 16 & 08 & 13 \\
\hline 4b & 06 & 11 & 12 & 07 \\
\hline 4c & 09 & 12 & 18 & 15 \\
\hline 4d & 13 & 17 & 17 & 21 \\
\hline 4e & 19 & 16 & 13 & 15 \\
\hline
\end{tabular}




\section{RESULTS}

The IR spectrum of compounds in $\mathrm{KBr}$ shows the characteristic band in the region of $1700 \pm 100 \mathrm{~cm}^{-1}$ which indicate the presence of $\mathbf{- C}=\mathbf{O}$ group. ${ }^{1} \mathrm{H}$ NMR spectrum of compounds shows doublet of $-\mathbf{C O}-\mathbf{C H}=$ at $\delta 6.9$ confirmed the presence of chalcone moiety. Result of IR and ${ }^{1} \mathrm{H}$ NMR analysis confirmed formation of desired products.

The environmentally benign synthesized compounds show the moderate to good antimicrobial activity against Rhizopus sp., Aspergillus flavus, Fusarium solani and Aspergillus niger.

\section{DISCUSSION}

QATBs capable of brominating a wide variety of organic substrates including aromatics in a safer way, either promoted by $\mathrm{V}_{2} \mathrm{O}_{5}-\mathrm{H}_{2} \mathrm{O}_{2}$ or catalyzed by $\mathrm{MoO}_{4}{ }^{2-} \mathrm{H}_{2} \mathrm{O}_{2}$. The scope of the protocols has been underscored, and the relevance to green chemistry has been highlighted.

Reactions of peroxometal intermediates can as well be exploited to generate an active brominating species $\left(\mathrm{Br}^{3-}\right)$ in situ which can also perform bromination of organic substrates very efficiently without compromising with the environmental acceptability.

\section{ACKNOWLEDGEMENT}

Author thankful to the Department of Chemistry, Department of Microbiology, SGB Amravati University, Amravati for providing the necessary facilities. Also to the Director, CIC, SGBAU, Amravati for IR spectrum analysis.

\section{REFERENCES}

1. Patil CB, Mahajan SK, et al. Chalcone: A Versatile Molecule. J. Pharm. Sci. \& Res. 2009; 1(3):11-22.

2. Suryawanshi SN, Chandra N, et al. Synthesis and bioevolution of novel chalcones. Journal of Medicinal Chemistry 2008; 43:2473-2478. http://dx.doi.org/10.1016/j.ejmech.2007.12.014 PMid:18243420

3. Susłow EK, Gładysz JD, et al. Microbial transformations of flavanone and 6-hydroxyflavanone by Aspergillus niger strains. Journal of
Molecular Catalysis B: Enzymatic 2006; 39:18-23. http://dx.doi.org /10.1016/j.molcatb.2006.01.020

4. Tepe B, Sokmen M, Daferera D, et al. Screening of the antioxidative and antimicrobial properties of the essential oils Pimpinella anisetum and Pimpinella flabellifolia from Turkey. Food Chemistry 2006; 97:719-724. http://dx.doi.org/10.1016/j.foodchem.2005.05.045

5. Funiss BS, Hannford AJ, Smith PW G, Tatchell A. R., Vogel's Textbook of practical organic chemistry, 5th ed. Pearson Education Publications; 2004.

6. Carruthers W, Coldham L, Modern methods of organic synthesis. 4th ed. Cambridge university press; 2004. http://dx.doi.org/10.1017/ CBO9780511811494

7. Walton B, Jean EC, et al. The mechanism of the antibiotic action of clavacin and penicillinic acid. J. Am. Chem. Soc. 1945; 67:112. http://dx.doi.org/10.1021/ja01217a038

8. Norman ROC, Taylor R. Electrophilic substitition in benzenoid compounds, New York: American Elsevier, 1965.

9. Shah NN, Kendre MM, Dhole JA, et al. Synthesis and antimicrobial studies of a novel series of piperazine chalcones. Der Chemica Sinica 2011; 2(1):33-37.

10. Solankee AN, Patel KP, et al. A convenient synthesis of chalcones, aminopyrimidines and Phenylpyrazolines. Der Chemica Sinica 2011, 2(5):1-7.

11. Naik S, Kavala V, et al. Tetrabutylammonium tribromide mediated condensation of carboxylic acids with alcohols. ARKIVOC 2006; (i): $119-127$.

12. Kamble VM, Hatnapure GD, et al. Synthesis and biological evaluation of a novel series of methoxylated chalcones as antioxidant and antimicrobial agents. J. Chem. Pharm. Res. 2011; 3(6):639-648.

13. Rahman MA, Chalcone: A Valuable Insight into the Recent Advances and Potential Pharmacological Activities. Chemical Sciences Journal 2011; CSJ-29:1-5.

14. Syam S, Abdelwahab SI, et al. Synthesis of Chalcones with Anticancer Activities. Molecules 2012; 17:6179-6195. http://dx.doi.org/10.3390/ molecules17066179 PMid:22634834

15. Tran TD, Nguyen T.T.N, et al. Synthesis and Antibacterial Activity of Some Heterocyclic Chalcone Analogues Alone and in Combination with Antibiotics, Molecules 2012; 17:6684-6696. http://dx.doi.org/ 10.3390/molecules17066684 PMid:22728362

Cite this article as:

Mayur R. Adokar. Synthesis and green bromination of some chalcones and their antimicrobial screening. Int. Res. J. Pharm. 2013; 4(4):194-196 